\title{
Cannabinoid Receptor CB2 Is Involved in Tetrahydrocannabinol-Induced Anti-Inflammation against Lipopolysaccharide in MG-63 Cells
}

\author{
Lei Yang, ${ }^{1,2}$ Fei-Fei Li, ${ }^{1}$ Yu-Chen Han, ${ }^{1}$ Bin Jia, ${ }^{3}$ and Yin Ding ${ }^{1}$ \\ ${ }^{1}$ State Key Laboratory of Military Stomatology, Department of Orthodontics, School of Stomatology, \\ Fourth Military Medical University, Xian, Shaanxi 710032, China \\ ${ }^{2}$ Department of Stomatology, The 264th Hospital of PLA, Taiyuan, Shanxi 030001, China \\ ${ }^{3}$ Department of Orthopaedics, Xijing Hospital, Fourth Military Medical University, Xian, Shaanxi 710032, China \\ Correspondence should be addressed to Yin Ding; dingyinfmmu@sohu.com
}

Received 21 November 2014; Revised 22 December 2014; Accepted 24 December 2014

Academic Editor: Fulvio D’Acquisto

Copyright (C) 2015 Lei Yang et al. This is an open access article distributed under the Creative Commons Attribution License, which permits unrestricted use, distribution, and reproduction in any medium, provided the original work is properly cited.

\begin{abstract}
Cannabinoid $\Delta$ 9-tetrahydrocannabinol (THC) is effective in treating osteoarthritis (OA), and the mechanism, however, is still elusive. Activation of cannabinoid receptor CB2 reduces inflammation; whether the activation CB2 is involved in THC-induced therapeutic action for $\mathrm{OA}$ is still unknown. Cofilin-1 is a cytoskeleton protein, participating in the inflammation of OA. In this study, MG-63 cells, an osteosarcoma cell-line, were exposed to lipopolysaccharide (LPS) to mimic the inflammation of OA. We hypothesized that the activation of CB2 is involved in THC-induced anti-inflammation in the MG-63 cells exposed to LPS, and the anti-inflammation is mediated by cofilin-1. We found that THC suppressed the release of proinflammatory factors, including tumor necrosis factor $\alpha$ (TNF- $\alpha$ ), interleukin- (IL-) $1 \beta$, IL-6, and IL-8, decreased nuclear factor- $\kappa \mathrm{B}$ (NF- $\kappa \mathrm{B}$ ) expression, and inhibited the upregulation of cofilin-1 protein in the LPS-stimulated MG-63 cells. However, administration of CB2 receptor antagonist or the CB2-siRNA, not CB1 antagonist AM251, partially abolished the THC-induced anti-inflammatory effects above. In addition, overexpression of cofilin-1 significantly reversed the THC-induced anti-inflammatory effects in MG-63 cells. These results suggested that CB2 is involved in the THC-induced anti-inflammation in LPS-stimulated MG-63 cells, and the anti-inflammation may be mediated by cofilin-1.
\end{abstract}

\section{Introduction}

Oversecretion of proinflammatory factors from osteoblasts plays vital roles in the progress of osteoarthritis $[1,2]$, and high levels of proinflammatory factors in bones and joints induce pain, cartilage loss, and even joint dysfunction $[3,4]$. Therefore, reducing the release of proinflammatory factors from osteoblasts is an effective therapy for OA. Traditional anti-inflammatory drugs, including steroidal antiinflammatory drugs and nonsteroid anti-inflammatory drugs (NSAID), are effective in alleviating the symptoms of OA [5, 6]. However, long-term use of these drugs brings about many side effects, such as gastritis, gastric ulcer, and/or immune suppression $[5,7]$. Therefore, a novel anti-inflammatory drug with mild side effects is needed urgently in the treatment of OA.

Cannabinoid $\Delta 9$-tetrahydrocannabinol (THC) is a main bioactive component from marijuana [8], and THC is effective in treating OA [9]; however, the mechanism is still not clear. THC exerts bioactivities by activating cannabinoid receptors [10]. At present, two main cannabinoid receptors have been discovered, including CB1 and CB2. Activation of $\mathrm{CB} 1$ receptor is associated predominantly with a dampening down of neuronal excitability, whereas activation of CB2 receptors is related to reducing immune cell function, including decreases of proinflammatory factors release [11]. In addition, CB2 receptor is expressed in osteoarthritis joints. Therefore, we aimed at $\mathrm{CB} 2$ receptor, not $\mathrm{CB} 1$, as one of the research 
targets in this study. Cofilin is a cytoskeleton protein family, including nonmuscle cofilin (cofilin-1), muscle cofilin (cofilin-2), and actin depolymerizing factor (ADF). Cofilin-1 and $\mathrm{ADF}$ are primarily expressed in nonmuscle mammalian cells, and cofilin-1 predominates [12]. Moreover, cofilin-1 is associated with many inflammatory conditions, such as OA and inflammatory pain $[13,14]$, and some investigations indicated that overexpression of cofilin-1 can decrease glucocorticoid receptor expression and NF- $\kappa \mathrm{B}$ activity $[15,16]$. However, whether cofilin-1 is involved in the therapeutic effects of THC in treating OA is still unclear.

MG-63 cell is an osteosarcoma cell-line, used widely to mimic osteoblasts in vitro [17]. Lipopolysaccharide (LPS) is a component of the outer membrane of gram-negative bacteria, which has been used mainly as a proinflammatory substance in several investigations [18]. And MG-63 cells exposed to LPS can be used as an inflammatory model of OA in vitro [19].

In this study, we hypothesized that cannabinoid CB2 receptor is involved in THC-induced anti-inflammation in LPS-stimulated MG-63 cells, and the THC-induced antiinflammation may be mediated by cofilin-1 protein.

\section{Materials and Methods}

2.1. Cell Culture and Reagents. MG-63, an osteogenic human osteosarcoma cell-line, was obtained from the America Type Culture Collection (ATCC). Cells were cultured in Minimum Essential Medium Eagle with Earl's salts (MEM) medium (Hyclone, USA) containing 10\% fetal bovine serum (Hyclone, USA), $100 \mathrm{U} / \mathrm{mL}$ penicillin, and $0.1 \mathrm{mg} / \mathrm{mL}$ streptomycin in a humidified atmosphere containing $5 \% \mathrm{CO}_{2}$ and $95 \%$ air at $37^{\circ} \mathrm{C}$. THC, LPS, and doxycycline were purchased from Sigma-Aldrich (St. Louis, MO, USA). CB2 antagonist AM630 and CB1 antagonist AM251 were obtained from Tocris Bioscience (UK). Anti-CB2 antibody and anti-cofilin-1 antibody were purchased from the Abcam (Cambridge, UK).

2.2. Experimental Protocols. The MG-63 cells were divided into five groups, including control, LPS, THC + LPS, AM630 + THC + LPS, and AM630 alone groups. After the treatments, immunocytochemistry staining and western blot were used to investigate the expression of $\mathrm{CB} 2$ receptor in the cells (Figure 1(a)). Then, the cells were assigned into seven groups, including control, LPS, THC + LPS, AM630 + THC + LPS, AM630 alone, AM251 + THC + LPS, and AM251 alone groups. After the treatments, inflammatory factors levels in the supernatants were evaluated by enzymelinked immunosorbent assay (ELISA) kits (Figure 1(b)). To further determine the role of $\mathrm{CB} 2$ in the THC-induced antiinflammatory effects in MG-63 cells, the cells were divided into five groups, including control, LPS, THC + LPS, CB2siRNA + THC + LPS, and scrambled- (SC-) siRNA + THC + LPS groups, after the treatments as shown in this figure, and western blot and ELISA kits were used to evaluate NF$\kappa \mathrm{B}$ expression and inflammatory factors release, respectively (Figure 1(c)). Then the MG-63 cells were divided into five groups, including control, LPS, THC + LPS, doxycycline
$(\mathrm{DOX})+$ THC + LPS, and DOX alone groups, after the treatments, and western blot and ELISA kits were used to evaluate cofilin-1 expression and inflammatory factors release, respectively (Figure 1(d)).

2.3. Enzyme-Linked Immunosorbent Assay (ELISA). The release of TNF- $\alpha$, IL- $1 \beta$, IL- 6 , and IL- 8 from the LPS-stimulated MG-63 cells was determined by the corresponding ELISA kit (R \& D Systems, Minneapolis, MN, USA) according to the instructions. The MG-63 cells were seeded in a 24well plate at a density of $5 \times 10^{4}$ cells/well. After the incubation for $24 \mathrm{~h}$, the supernatants were collected and centrifuged, and then the cell-free supernatants were used for ELISA assay.

2.4. Immunofluorescence Staining. The MG-63 cells were seeded into five confocal microscopy special dishes at a density of $2 \times 10^{4}$ cells/dish. After the treatments, the MG-63 cells were washed three times with phosphate buffer solution (PBS) and then fixed with 4\% paraformaldehyde solution for $30 \mathrm{~min}$ and blocked with $50 \mathrm{mg}$ bovine serum albumin (BSA) $/ \mathrm{mL}$ in PBS for $30 \mathrm{~min}$. Cells were incubated with primary anti-CB2 antibody $(1: 50)$ overnight at $4^{\circ} \mathrm{C}$ and then washed three times with PBS, before incubation with Cy3labeled secondary antibody (1:200, Beyotime, China) for $1 \mathrm{~h}$ at room temperature. The $4^{\prime}, 6$-diamidino-2-phenylindole (DAPI) staining solution $(200 \mu \mathrm{L})$ was added into each dish for $5 \mathrm{~min}$, and then the dishes were washed three times with PBS. CB2 expression was observed by a laser scanning confocal microscope (FV10i, Olympus, Japan) $($ Excitation = $550 \mathrm{~nm}$, Emission $=570 \mathrm{~nm}$ ).

2.5. Western Blot. After the treatments, the MG-63 cells were washed twice with ice-cold PBS (pH 7.2) and harvested with ice-cold PBS and then centrifuged at $14000 \times \mathrm{g}$ for $5 \mathrm{~min}$ at $4^{\circ} \mathrm{C}$. Nuclear and cytosolic extracts were prepared using a Nuclear and Cytoplasmic Protein Extraction Kit (Beyotime, China) according to the manufacturer's instructions. The protein concentration was determined by using the Bradford assay. The samples were fractionated on $10 \%$ SDS-polyacrylamide gel electrophoresis (SDS-PAGE) and transferred to polyvinylidene fluoride membranes (Chemicon International, Millipore, Billerica, MA, USA). The membranes were blocked for $1 \mathrm{~h}$ at room temperature with $5 \%$ nonfat milk in PBS-Tween $20(0.1 \%)$ and then incubated with different primary antibodies (CB2, 1:200; NF- $\kappa$ B, 1:2000; cofilin, $1: 2000)$. The membrane was incubated with electrochemiluminescence reagent for $10 \mathrm{~min}$ and exposed to X-ray film. The signals were quantified by densitometry using a western blotting detection system (Alpha Innotech, USA). $\beta$-actin and GAPDH (Cowin Inc. China) served as the loading control.

2.6. CB2 Small Interfering RNA. MG-63 cells were transfected with specific CB2 targeting small interfering RNA (siRNA) designed to knockdown CB2 protein expression (Dharmacon, USA). Briefly, MG-63 cells (70\% confluent) were transfected with 100 pmol CB2-siRNA or scrambled- (SC-) 


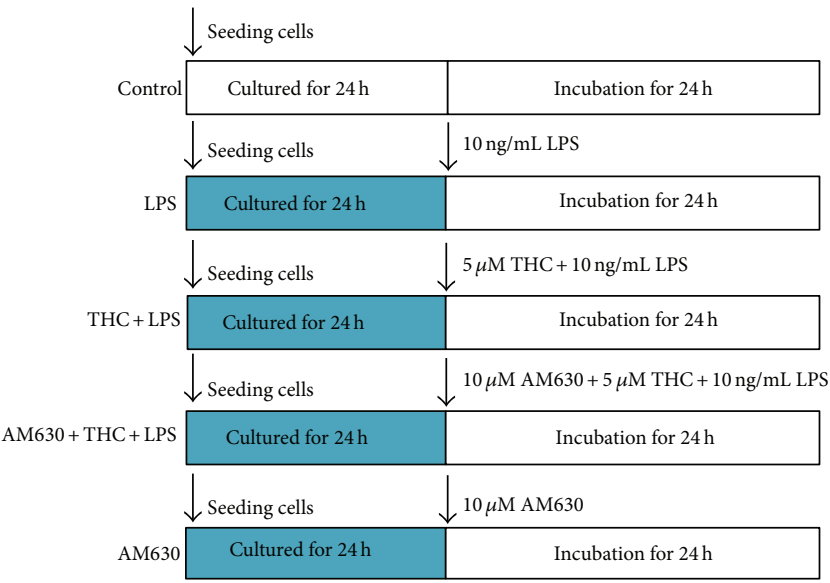

(a)

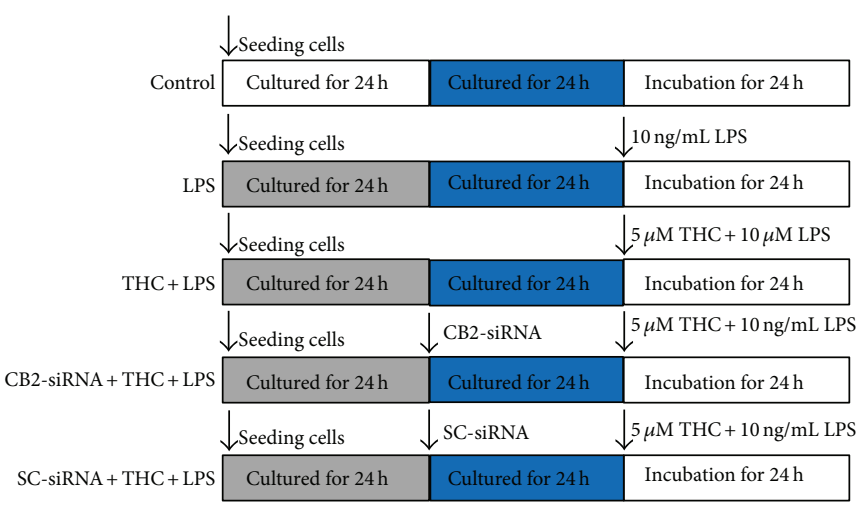

(c)

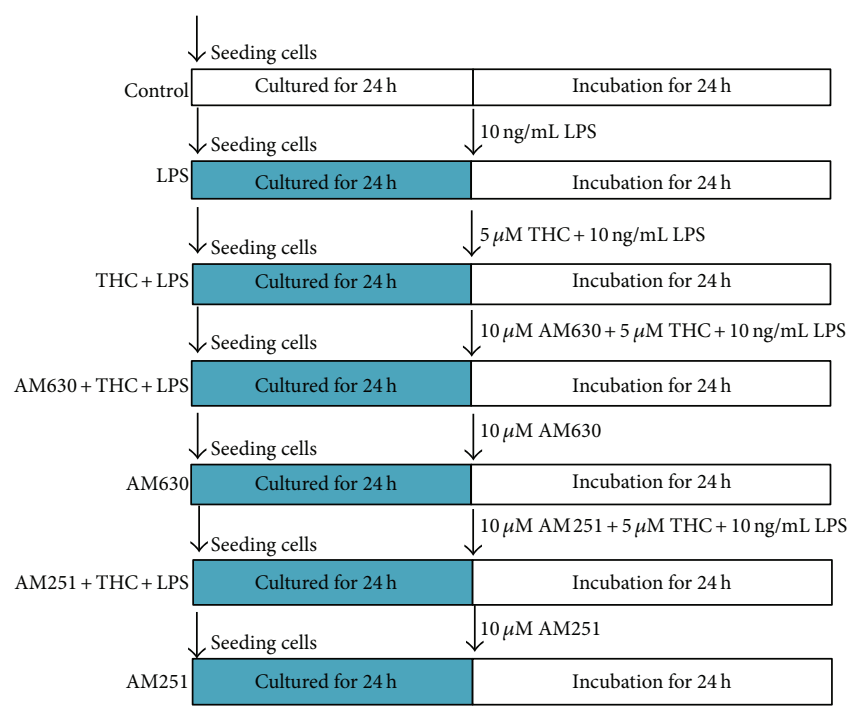

(b)

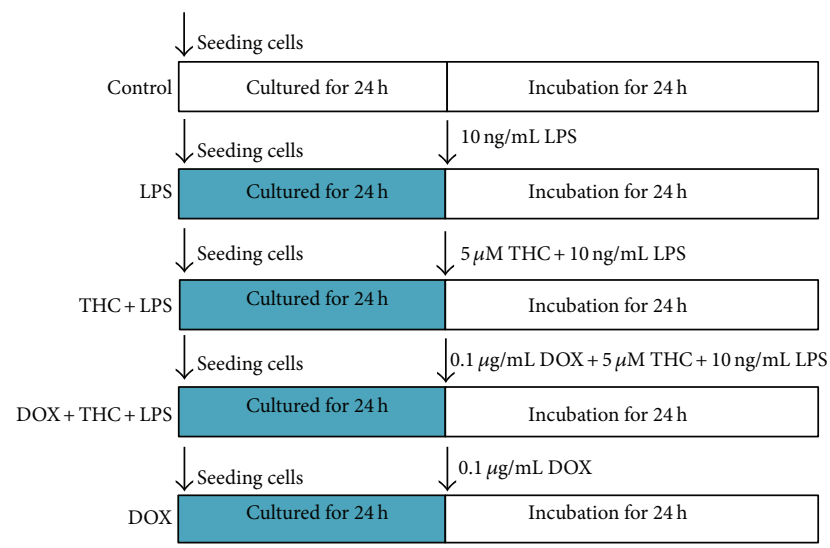

(d)

FIGURE 1: Experimental protocol diagram. (a) The MG-63 cells were assigned into five groups, including control, LPS, THC + LPS, AM630 + THC + LPS, and AM630 groups. After the treatments for $24 \mathrm{~h}$, immunocytochemistry and western blot were taken to investigate the expression of CB2 receptor. (b) The MG-63 cells were assigned into seven groups as shown in this figure. After the treatments, ELISA was used to evaluate the inflammatory factors concentrations in the supernatants. (c) The MG-63 cells were assigned into five groups, including control, LPS, THC + LPS, CB2-siRNA + THC + LPS, and SC-siRNA + THC + AM630 groups. After the treatments, western blot was taken to investigate the expression of CB2 receptor and ELISA was used to assess the inflammatory factors release. (d) The cells were divided into control, LPS, THC + LPS, doxycycline (DOX) + THC + LPS, and DOX groups, western blot was taken to investigate the expression of cofilin-1 protein, and ELISA was taken to evaluate the concentrations of proinflammatory factors in the supernatants.

siRNA using LipofectAMINE 2000 (Invitrogen) according to the manufacturer's protocol. After the transfection for $24 \mathrm{~h}$, the cells were then treated with different drugs and assessed.

2.7. Statistical Analysis. The results of this study were expressed as means $\pm \mathrm{SD}$, which were obtained from at least three independent experiments for each condition. The statistical significance of the results was evaluated with one-way variance analysis (one-way ANOVA), followed by Tukey's multiple comparison test. $P<0.05$ was taken to indicate statistical significance.

\section{Results}

3.1. THC Attenuated LPS-Induced Inflammation in MG-63 Cells. The MG-63 cells were exposed to different concentrations of LPS for $24 \mathrm{~h}$ (Figure 2(a)), causing a dose-dependent release of IL- 6 from the cells. IL- 6 is a proinflammatory factor, which was evaluated as an index reflecting the inflammation level of the LPS-treated MG-36 cells. The presence of $10 \mathrm{ng} / \mathrm{mL}$ LPS for $24 \mathrm{~h}$ increased the IL- 6 level to $714.2 \pm$ $55.4 \mathrm{pg} / \mathrm{mL}$, compared with $38.5 \pm 13.2 \mathrm{pg} / \mathrm{mL}$ of the control $(P<0.05)$ in the supernatants. We used $10 \mathrm{ng} / \mathrm{mL}$ LPS in the subsequent experiments. Coadministration of $0.5,5$, 


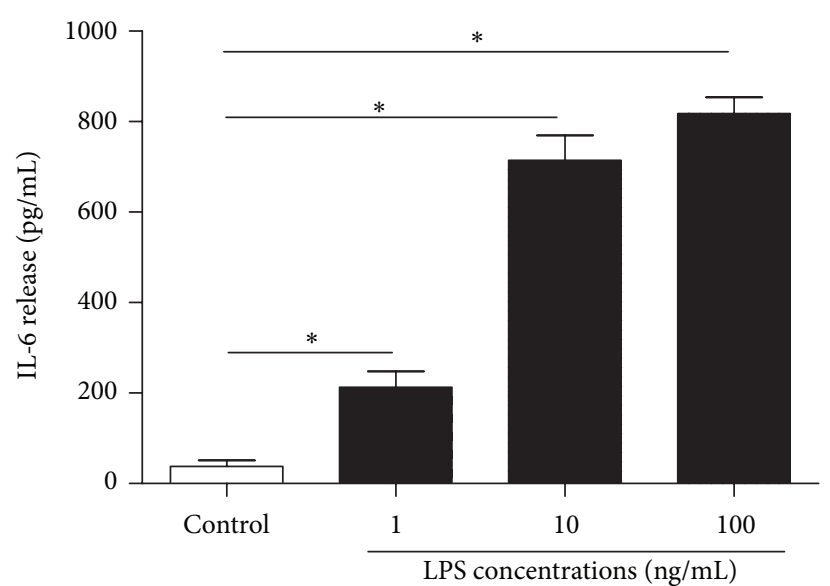

(a)

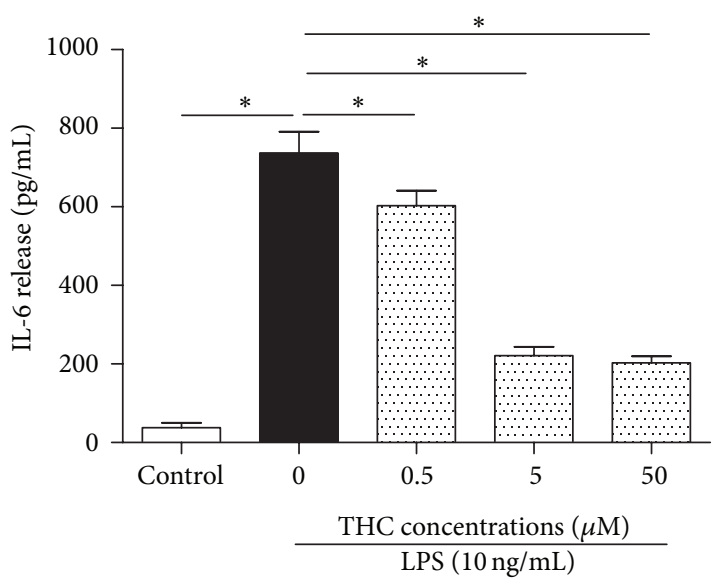

(b)

FIGURE 2: THC decreased LPS-induced IL-6 release from MG-63 cells dose-dependently. (a) MG-63 cells were treated with 0, 1, 10, and $100 \mathrm{ng} / \mathrm{mL}$ LPS for $24 \mathrm{~h}$. (b) The MG-63 cells were treated with different concentrations of THC plus $10 \mathrm{ng} / \mathrm{mL}$ LPS for $24 \mathrm{~h}$. IL-6 release was determined by ELISA kits. Results are means \pm SD $(n=8) .{ }^{*}: P<0.05$.

and $50 \mu \mathrm{M}$ THC significantly reduced the IL- 6 release from the LPS-stimulated cells (Figure 2(b)), suggesting that THC induced an anti-inflammation. We used $5 \mu \mathrm{M}$ THC in the subsequent experiments.

3.2. THC Upregulated the Expression of CB2 Receptor in MG63 Cells. Immunocytochemistry and western blot were used to determine the expression of CB2 protein in MG63 cells. We observed that LPS alone did not induce a marked change of CB2 protein expression (Figures 3(a)-3(b)), and THC (5 $\mu \mathrm{M})$ upregulated CB2 protein expression. However, coadministration of CB2 antagonist AM630 $(10 \mu \mathrm{M})$ significantly inhibited the THC-induced upregulation of CB2 expression and did not induce a marked change of CB2 expression alone.

\subsection{CB2, Not CB1, Was Involved in THC-Induced Reduction} of Proinflammatory Factors Release and NF- $\kappa B$ Expression. Incubation with LPS $(10 \mathrm{ng} / \mathrm{mL})$ for $24 \mathrm{~h}$ sharply increased the concentrations of TNF- $\alpha$, IL- $1 \beta$, IL- 6 , and IL- 8 in the supernatants $(P<0.05)$ and the upregulation of NF- $\kappa \mathrm{B}$ expression in MG-63 cells, and coadministration of THC $(5 \mu \mathrm{M})$ significantly reduced the release of the proinflammatory factors (Figures 4(a)-4(d)) and the upregulation of NF- $\kappa$ B (Figures 5(a)-5(b)). However, CB2 antagonist AM630, not CB1 antagonist AM251, inhibited the THCinduced reduction of release of proinflammatory factors and $\mathrm{NF}-\kappa \mathrm{B}$ expression, indicating that the THC-induced antiinflammatory effects may be mediated by CB2 receptor, not by CB1.

\subsection{CB2-siRNA Reversed THC-Induced Anti-Inflammatory} Effects. To further determine whether the THC-induced anti-inflammation was mediated by CB2 receptor in MG-63 cells, we used CB2-siRNA to knockdown the CB2 protein expression in MG-63 cells. We found that CB2-siRNA was effective in reducing the expression of CB2 (Figure 6(a)). In addition, CB2-siRNA reversed the THC-induced inhibition of NF- $\kappa \mathrm{B}$ expression (Figure 6(b)) and proinflammatory factors release (Figures 6(c)-6(f)), including TNF- $\alpha$, IL-1 $\beta$, IL-6, and IL-8 $(P<0.05)$.

3.5. Cofilin-1 Was Involved in the THC-Induced Anti-Inflammatory Effect in MG-63 Cells. Incubation with $10 \mathrm{ng} / \mathrm{mL}$ LPS for $24 \mathrm{~h}$ markedly increased the cofilin-1 expression in MG63 cells $(P<0.05)$ compared with the cells cultured in drug-free medium, and coadministration of $5 \mu \mathrm{M}$ THC inhibited the cofilin-1 expression significantly (Figure 6(a)). CB2 antagonist AM630 partially reversed the THC-induced inhibition of cofilin-1 expression.

In order to further determine the role of cofilin-1 in THC-induced anti-inflammation in the MG- 63 cells, we used doxycycline, which can upregulate the expression of cofilin1 significantly in vitro $[20,21]$. We observed that $0.1 \mu \mathrm{g} / \mathrm{mL}$ doxycycline markedly increased the expression of cofilin1 in MG-63 cells (Figure 6(b)). And coadministration of $0.1 \mu \mathrm{g} / \mathrm{mL}$ doxycycline partially reversed THC-induced decrease of IL- 6 and TNF- $\alpha$ release (Figures $6(c)-6(d)$ ). These findings indicated that cofilin-1 was involved in the THCinduced anti-inflammation via CB2 in the MG-63 cells exposed to LPS.

\section{Discussion}

In this study, we found that the presence of $5 \mu \mathrm{M}$ THC attenuated the inflammation in MG-63 cells exposed to $10 \mathrm{ng} / \mathrm{mL}$ LPS. Meanwhile THC increased CB2 protein expression and inhibited the upregulation of NF- $\kappa \mathrm{B}$ and cofilin-1 expression in the MG-63 cells. However, administration of CB2 antagonist AM630 or CB2-siRNA, not CB1 antagonist AM251, partially reversed the THC-induced anti-inflammatory effects. 


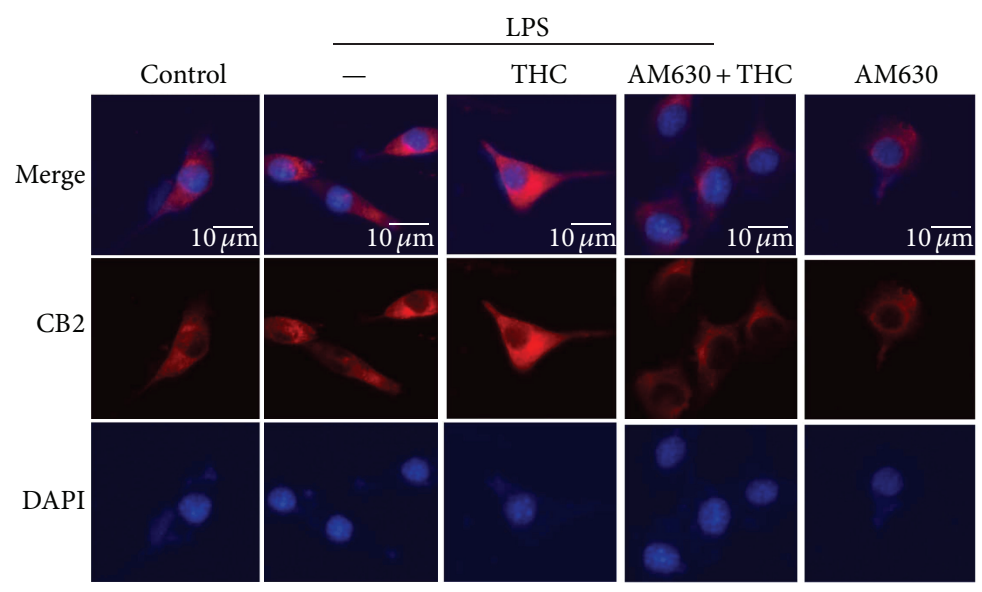

(a)

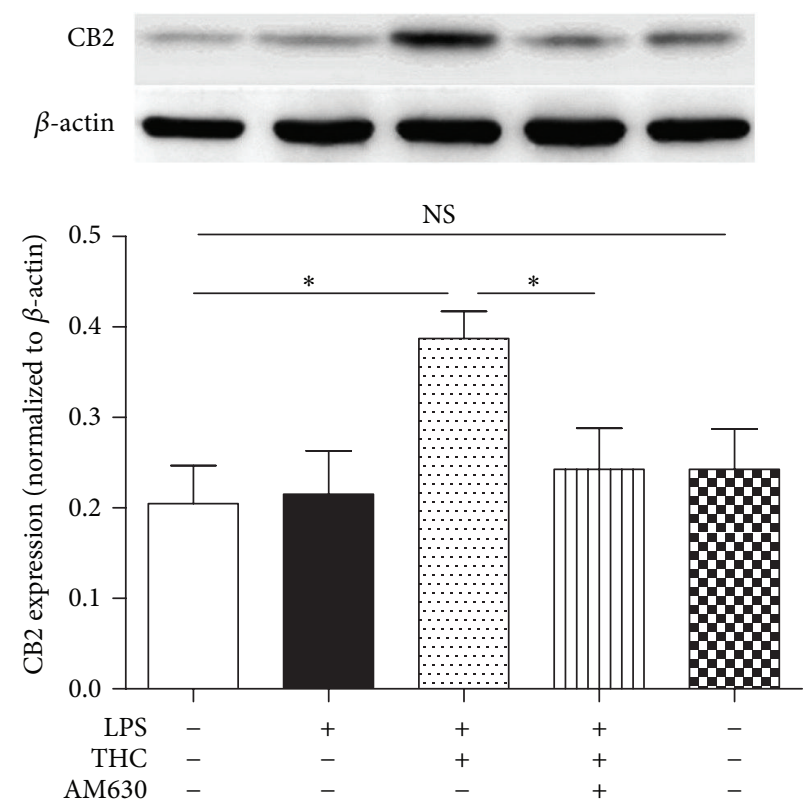

(b)

FIGURE 3: THC upregulated CB2 receptor expression. Immunofluorescent staining (a) and western blot (b) were used to determine the CB2 protein expression. The cells were treated with or without $10 \mathrm{ng} / \mathrm{mL}$ LPS for $24 \mathrm{~h}$ in the presence or absence of $5 \mu \mathrm{M}$ THC or $10 \mu \mathrm{M}$ AM630 (CB2 receptor antagonist). The $\mathrm{CB} 2$ receptor expression (red) was observed by a confocal microscope, and stronger signal indicated higher expression of CB2 protein. Nuclei were counter-stained with DAPI (blue). Bar $=10 \mu \mathrm{m}$. Results are means \pm SD $(n=6)$. ${ }^{*}: P<0.05 ; \mathrm{NS}$ : no significance.

Moreover, upregulation of cofilin-1 protein partially abolished the THC-induced anti-inflammation (Figure 7). These findings indicated that $\mathrm{CB} 2$ receptor is involved in the THCinduced anti-inflammation in the MG-63 cells exposed to LPS, and the anti-inflammation may be mediated by cofilin-1 protein.

$\mathrm{OA}$ is one of the most common causes of disability in elder adults, especially in the population aged over 65 years. Oversecretion of proinflammatory cytokines, including TNF- $\alpha$, IL- 6 , and IL- $1 \beta$, contributes to the severity and the progression of $\mathrm{OA}$ [3]. High levels of proinflammatory cytokines in bones and joints can damage articular cartilage by inducing chondrocyte apoptosis and proteoglycan depletion
[22]. Therefore, inhibiting the secretion of proinflammatory cytokines is vital to prevent the progression of cartilage degeneration at the initial stage of OA [5]. At present, corticosteroids and NSAID are used widely to attenuate the inflammation of $\mathrm{OA}[23,24]$. As these drugs just relieve the symptoms of OA rather than cure the disease, side effects, including vomiting, gastritis, and immune suppression, emerged with repeated and long-term use $[5,25]$. Thus, a drug that can treat OA with slight and less side effects is needed urgently.

THC is main cannabinoid compounds from marijuana, which has a number of therapeutic applications, including anti-inflammation and analgesic effects [26]. However, THC 


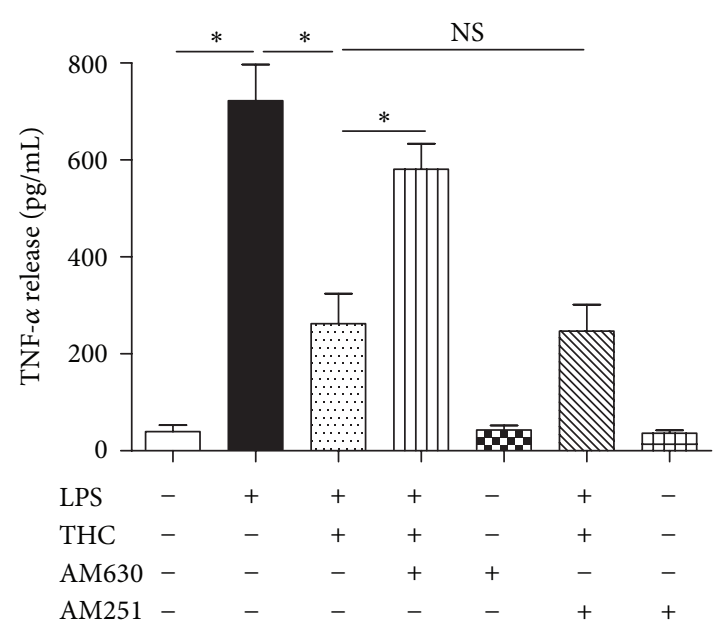

(a)

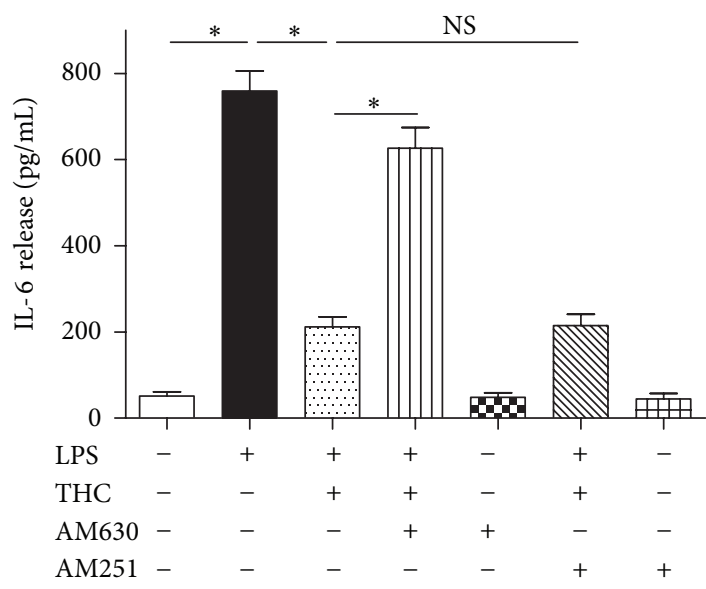

(c)

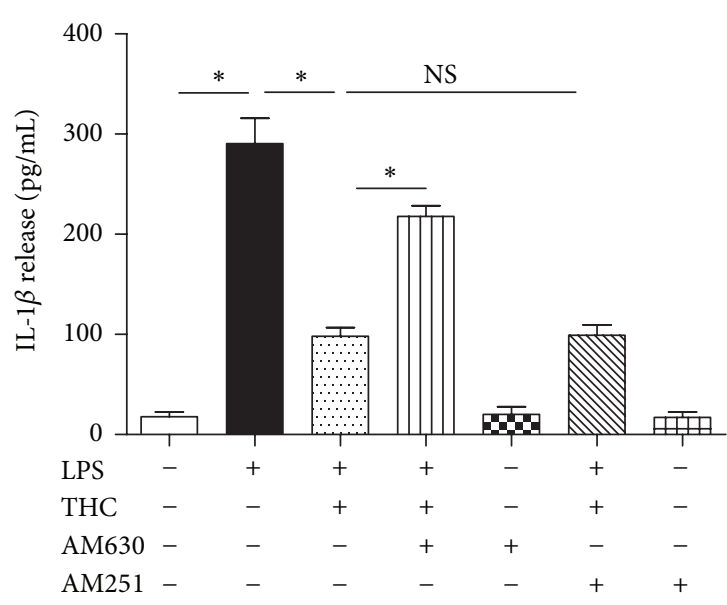

(b)

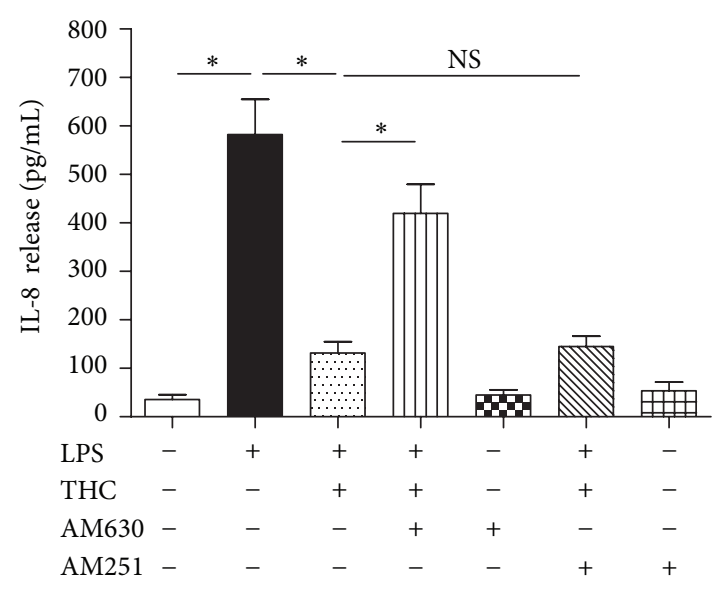

(d)

Figure 4: THC decreased the release of TNF- $\alpha$, IL-1 $\beta$, IL-6, and IL- 8 from LPS-stimulated MG-63 cells. TNF- $\alpha$ (a), IL-1 $\beta$ (b), IL-6 (c), and IL-8 (d) release were determined by ELISA kits. THC $(5 \mu \mathrm{M})$ decreased $10 \mathrm{ng} / \mathrm{mL}$ LPS-induced release of TNF- $\alpha$, IL-1 $\beta$, IL-6, and IL-8, and CB2 antagonist AM630 $(10 \mu \mathrm{M})$ reversed these effects. Results are means $\pm \mathrm{SD}(n=6) .{ }^{*}: P<0.05$; NS: no significance.

has rarely been well studied in treating OA and its therapeutic mechanism is still not clear. In most cases, THC is used as a painkiller, which relieves pain via activating cannabinoid and opioid receptors expressed in the brain [27]. Therefore, researchers paid more attention to the CNS system rather than the peripheral tissue during investigating the mechanism of THC in anti-inflammation. In this study, we found that THC attenuated LPS-induced proinflammatory factors release from the MG-63 cells, including TNF- $\alpha$, IL- $1 \beta$, IL6 , and IL-8, and THC reduced the upregulation of NF- $\kappa$ B expression in the MG-63 cells, indicating that the THCinduced anti-inflammatory effects may be associated with its anti-inflammation. Moreover, selective CB2 receptor antagonist AM630 or CB2-siRNA, not CB1 antagonist AM251, significantly reversed the THC-induced anti-inflammatory effects and the inhibition of NF- $\kappa \mathrm{B}$ expression, suggesting that the THC-induced anti-inflammation may be mediated by CB2 receptor in MG-63 cells. As one of the key molecules regulating the release of various inflammatory factors, the expression level of NF- $\kappa \mathrm{B}$ reflects the inflammation degree in cells. NF- $\kappa \mathrm{B}$ locates in the nucleus, and CB2 is mainly expressed in the cell membrane and cytoplasm $[28,29]$; thus we infer that THC may activate CB2 receptors expressed in the cell membrane and cytoplasm of MG63 cells and then inhibit NF- $\kappa \mathrm{B}$ expression to reduce the inflammatory factors release from the MG-63 cells exposed to LPS. Similarly, Gondim et al. reported that CB2 is involved in electroacupuncture- (EA-) induced anti-inflammatory effects in a rat model of arthritis [30]. And Zarruk et al. reported that the activation of microglial CB2 receptor brings about neuroprotection against brain ischemic injury by decreasing the proinflammatory cytokines release in mice [31]. Although THC is a cannabinoid ligand for both $\mathrm{CB} 1$ and $\mathrm{CB} 2$ receptors, Newton and Klein described that THC downregulates serum IgE levels through $\mathrm{CB} 2$ receptor rather than $\mathrm{CB} 1$ receptor in an IgE induction model in mice [32]. These findings supported that activation of $\mathrm{CB} 2$ receptor may be involved in THC-induced anti-inflammation in MG-63 cells. 


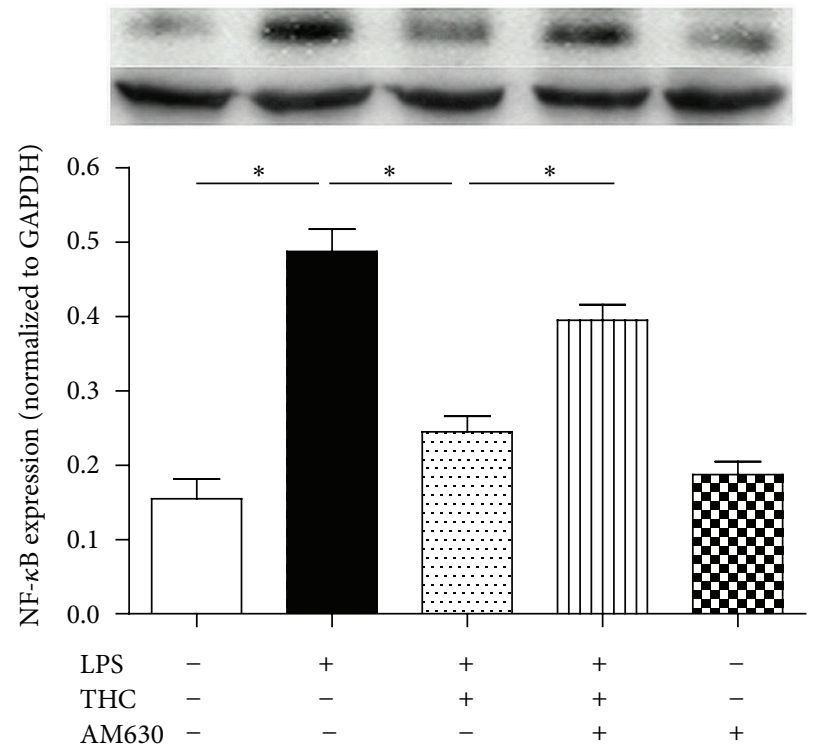

(a)

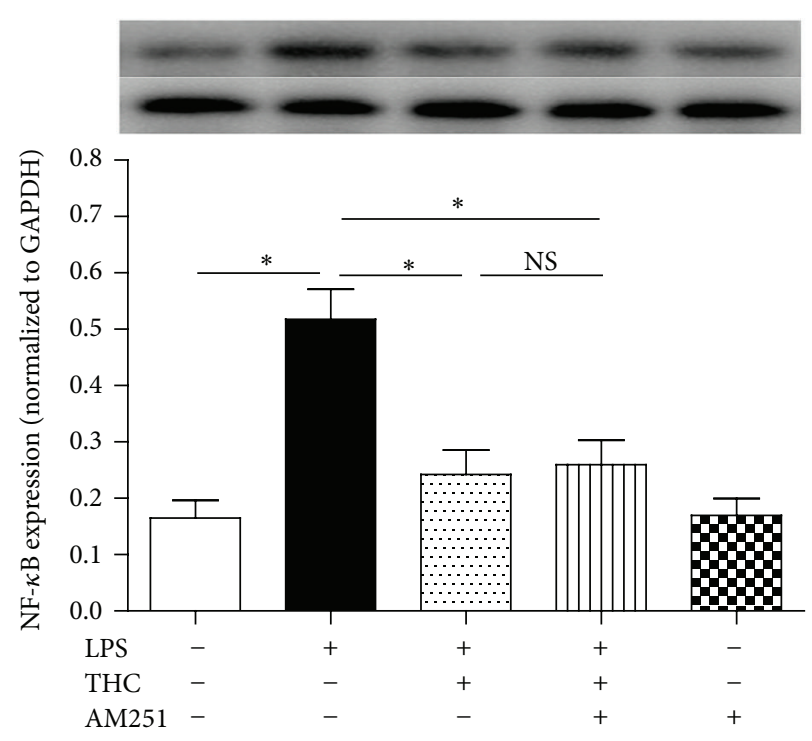

(b)

FIGURE 5: THC reduced NF- $\kappa$ B expression via CB2 receptor in LPS-stimulated MG-63 cells. NF- $\kappa$ B expression was assessed by western blot. THC reduced LPS-induced upregulation of NF- $\kappa$ B expression, and CB2 antagonist AM630 (a), not CB1 antagonist AM251 (b), partially abolished this effect. Results are means $\pm \mathrm{SD},(n=6) .^{*}: P<0.05$; NS: no significance.

Cofilin is a cytoskeleton protein family, which is known to promote actin depolymerization and maintain the stability of cell structure [33]. A study indicated that overexpression of cofilin can induce glucocorticoid resistance [15], and another study mentioned that JWH015, a selective CB2 agonist, modulated the activity of cofilin [34]. Cofilin is also an important signaling molecule for the cytoskeletal and migratory properties of trabecular meshwork cells [34]. The cofilin protein family consists of three isoforms, including cofilin-1, cofilin-2, and ADF. Cofilin-1 and ADF are mainly expressed in non-muscle tissue, and cofilin-1 predominates. Chiang et al. reported that cofilin-1 is involved in isoflurane(an inhaled anesthetic) induced anti-inflammatory effect [14]; besides CB2 could be activated by isoflurane [35], suggesting that cofilin-1 may be involved in the modulation of inflammation, which might be related to CB2 receptor. Therefore, we investigated cofilin-1 in THC-induced antiinflammatory effects in this study. We observed that CB2 antagonist AM630 reversed the THC-induced modulation of cofilin-1 expression in the LPS-stimulated MG-63 cells, and overexpression of cofilin- 1 abolished the THC-induced anti-inflammation in the cells, indicating that cofilin-1 may mediate the THC-induced anti-inflammatory effects via CB2 receptor. Moreover, Rom et al. reported that $\mathrm{CB} 2$ selective agonists GP1a and AM1241 increase the phosphorylation of cofilin in brain tissue, causing protection of blood-brain barrier against inflammatory leukocyte [36]. Therefore, we infer that THC-induced anti-inflammation may be related to the phosphorylation of cofilin in MG-63 cells exposed to LPS. However, how does THC modulate expression or phosphorylation of cofilin-1 protein? Further investigation is needed to answer this question.
There are still some limitations in our investigation. First, our study is in vitro; thus the results of this investigation should be further identified in in vivo study and clinical trials. Second, the MG-63 cells used here are an osteosarcoma cell-line, not primary osteoblasts, so the results of this study should be accepted cautiously. Third, we just upregulated the cofilin-1 expression in this study; how THC works is still unknown when cofilin-1 is downregulated.

\section{Conclusions}

Our study indicates that cannabinoid CB2 receptor is involved in THC-induced anti-inflammation in MG-63 cells exposed to LPS, and the anti-inflammatory effects may be mediated by cofilin-1 protein.

\section{Conflict of Interests}

The authors declare that they have no conflict of interests.

\section{Authors' Contribution}

Lei Yang, Fei-Fei Li, Yu-Chen Han, and Bin Jia contributed equally to this work and should be considered co-first authors.

\section{Acknowledgment}

This work was supported by the National Natural Science Foundation of China (no. 31200706). 

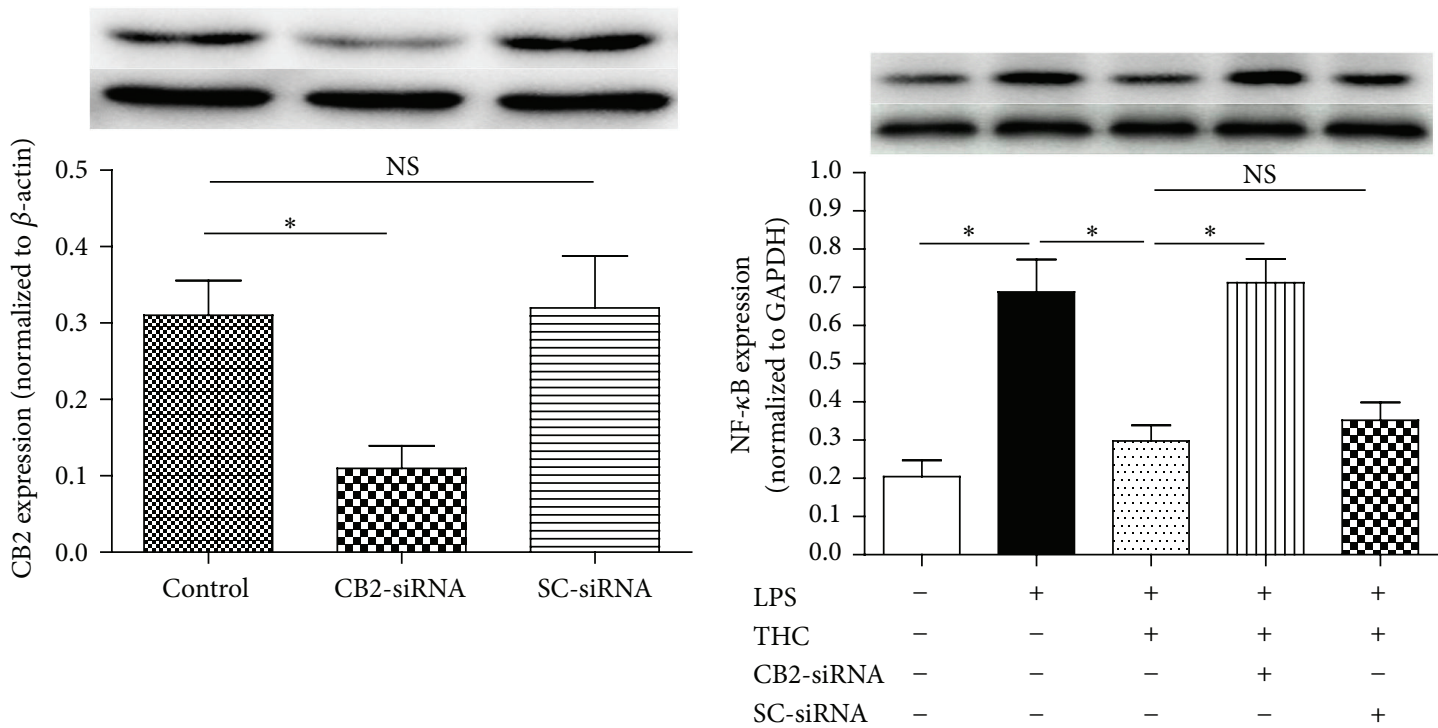

(a)

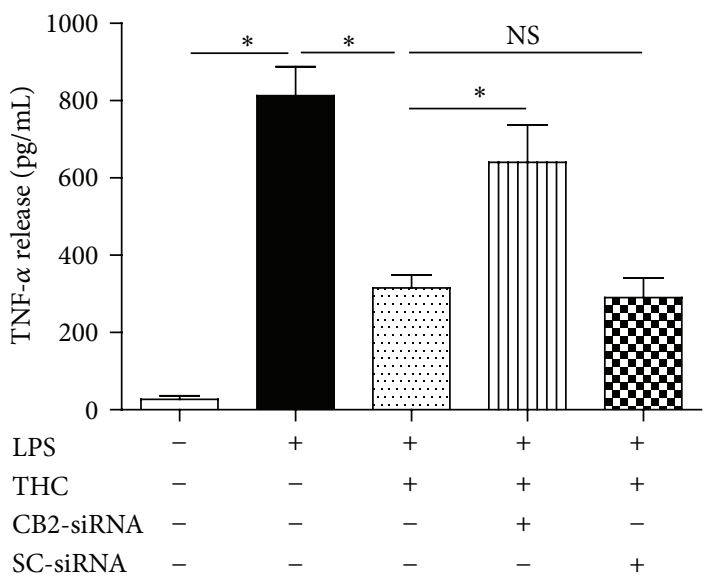

(c)

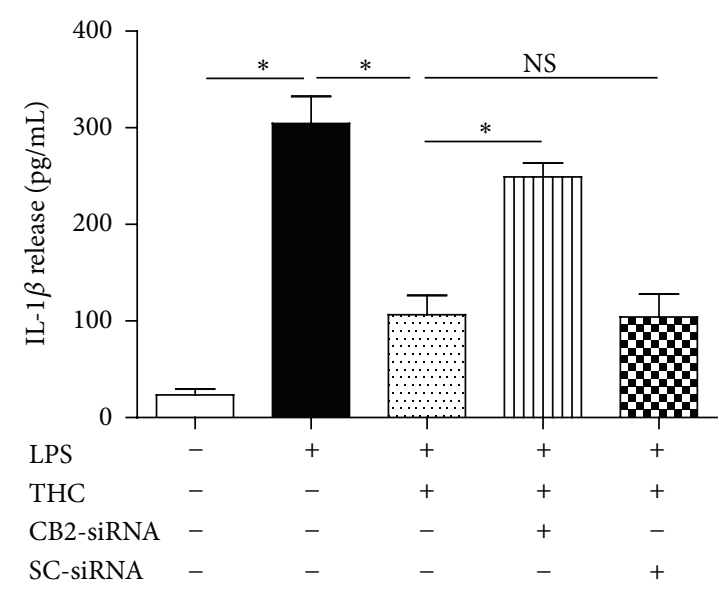

(d)
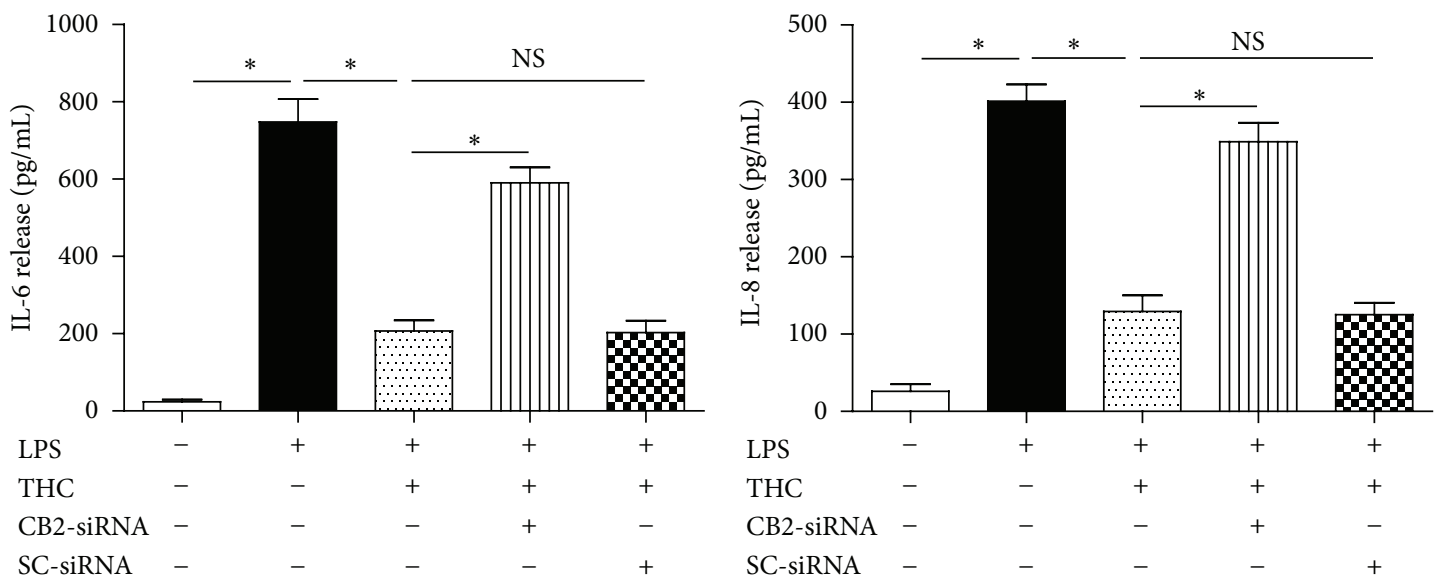

(e)

(f)

FIGURE 6: CB2-siRNA reversed THC-induced decrease of inflammatory factors release. MG-63 cells were assigned into five groups, control (no LPS, THC, or siRNA): cultured in drug-free medium; LPS: cells exposed to $10 \mathrm{ng} / \mathrm{mL}$ LPS for $24 \mathrm{~h}$; THC + LPS: cells exposed to $5 \mu \mathrm{M}$ THC plus $10 \mathrm{ng} / \mathrm{mL}$ LPS for $24 \mathrm{~h}$; CB2-siRNA + THC + LPS: cells incubated with CB2-siRNA for $24 \mathrm{~h}$ and then exposed to $5 \mu \mathrm{M}$ THC plus $10 \mathrm{ng} / \mathrm{mL}$ LPS for $24 \mathrm{~h}$; scrambled siRNA (SC-siRNA) + THC + LPS: cells incubated with SC-siRNA for $24 \mathrm{~h}$ and then exposed to $5 \mu \mathrm{M}$ THC plus $10 \mathrm{ng} / \mathrm{mL}$ LPS for $24 \mathrm{~h}$. (a) CB2-siRNA significantly downregulated the expression of CB2 receptor, assessed by western blot $(n=3)$. (b) CB2-siRNA significantly reversed THC-induced effect on NF- $\kappa$ B expression $(n=6)$. (c)-(f) CB2-siRNA significantly reversed THC-induced effects on the release of TNF- $\alpha$, IL- $1 \beta$, IL- 6 , and IL- $8(n=6)$. Results are means \pm SD. ${ }^{*}: P<0.05$; NS: no significance. 


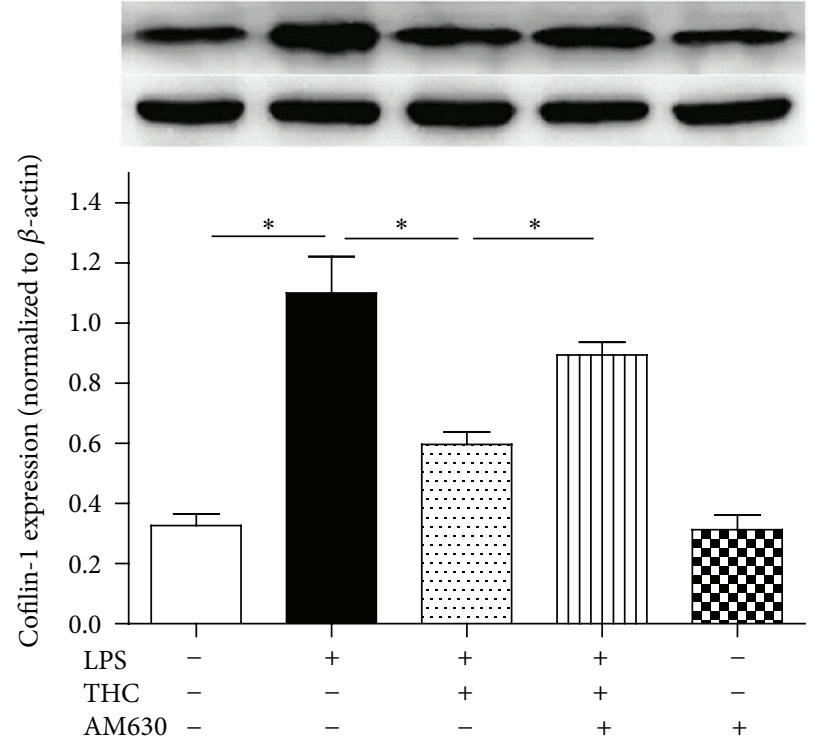

(a)

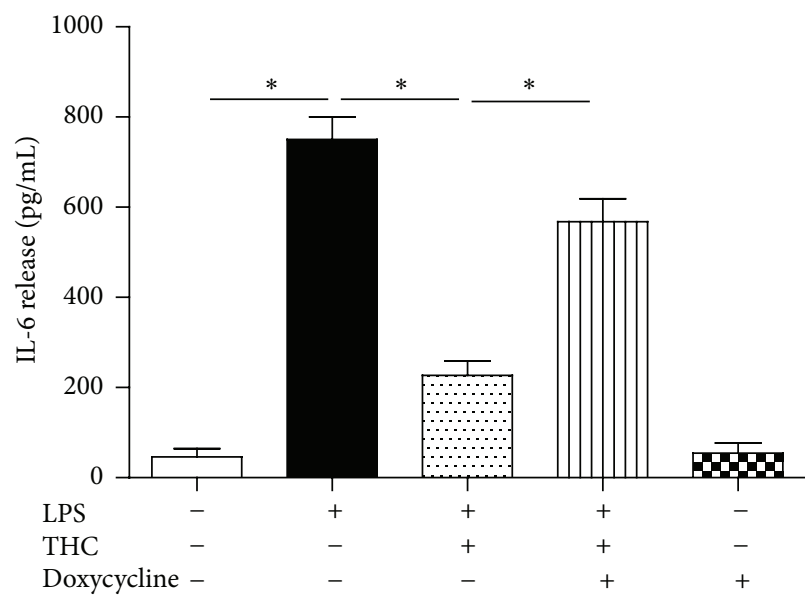

(c)

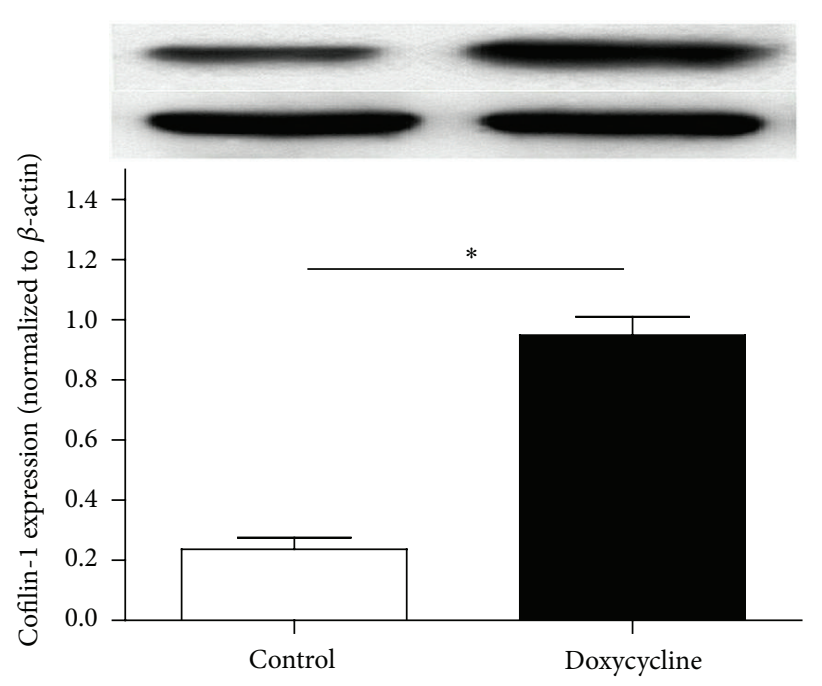

(b)

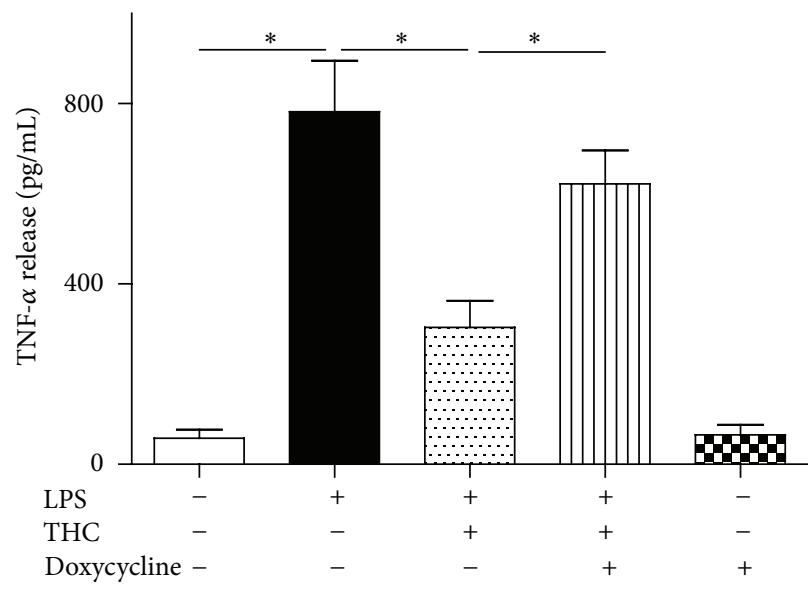

(d)

FIGURE 7: The upregulation of cofilin-1 inhibited the THC-induced anti-inflammation. (a) CB2 antagonist reversed the THC-induced effect on cofilin-1 expression. (b) Doxycycline induced an overexpression of cofilin-1 in the MG-63 cells. (c) Doxycycline abolished THC-induced reduction of IL-6 release. (d) Doxycycline abolished the THC-induced reduction of TNF- $\alpha$ release. The cells were treated with different drugs for $24 \mathrm{~h}$ (LPS: $10 \mathrm{ng} / \mathrm{mL}$; THC: $5 \mu \mathrm{M}$; AM630: $10 \mu \mathrm{M}$; doxycycline: $0.1 \mu \mathrm{g} / \mathrm{mL}$ ), western blot was performed to evaluate the cofilin-1 expression, and ELISA was used to test the concentrations of IL- 6 and TNF- $\alpha$ in the supernatants. Results are means \pm SD $(n=6) .{ }^{*}: P<0.05$.

\section{References}

[1] R. Sun, B. Zhang, L. Chen, and J. Sun, "Role of nuclear factor of activated T cells 1 in the pathogenesis of osteoarthritis," Experimental and Therapeutic Medicine, vol. 7, no. 1, pp. 195-198, 2013.

[2] X. Liu, Y. Xu, S. Chen et al., "Rescue of proinflammatory cytokine-inhibited chondrogenesis by the antiarthritic effect of melatonin in synovium mesenchymal stem cells via suppression of reactive oxygen species and matrix metalloproteinases," Free Radical Biology and Medicine, vol. 68, pp. 234-246, 2014.

[3] M. A. Karsdal, A. C. Bay-Jensen, R. J. Lories et al., "The coupling of bone and cartilage turnover in osteoarthritis: opportunities for bone antiresorptives and anabolics as potential treatments?" Annals of the Rheumatic Diseases, vol. 73, no. 2, pp. 336-348, 2014.
[4] S. Yang, C. E. Dubé, C. B. Eaton, T. E. McAlindon, and K. L. Lapane, "Longitudinal use of complementary and alternative medicine among older adults with radiographic knee osteoarthritis," Clinical Therapeutics, vol. 35, no. 11, pp. 1690-1702, 2013.

[5] Y. Tu, H. Xue, W. Francis et al., "Lactoferrin inhibits dexamethasone-induced chondrocyte impairment from osteoarthritic cartilage through up-regulation of extracellular signal-regulated kinase 1/2 and suppression of FASL, FAS, and Caspase 3," Biochemical and Biophysical Research Communications, vol. 441, no. 1, pp. 249-255, 2013.

[6] L. Gallelli, O. Galasso, D. Falcone et al., "The effects of nonsteroidal anti-inflammatory drugs on clinical outcomes, synovial fluid cytokine concentration and signal transduction pathways in knee osteoarthritis. A randomized open label trial," Osteoarthritis and Cartilage, vol. 21, no. 9, pp. 1400-1408, 2013. 
[7] A. Lanas, J. L. Goldstein, F. K. L. Chan et al., "Risk factors associated with a decrease $\geq 2 \mathrm{~g} / \mathrm{dL}$ in haemoglobin and/or $\geq 10 \%$ haematocrit in osteoarthritis patients taking celecoxib or a nonselective NSAID plus a PPI in a large randomised controlled trial (CONDOR)," Alimentary Pharmacology and Therapeutics, vol. 36, no. 5, pp. 485-492, 2012.

[8] R. Chen, J. Zhang, N. Fan et al., " $\Delta^{9}$-THC-caused synaptic and memory impairments are mediated through COX-2 signaling," Cell, vol. 155, no. 5, pp. 1154-1165, 2013.

[9] I. G. Otterness, M.-P. H. Le Graverand, and F. Eckstein, "Allometric relationships between knee cartilage volume, thickness, surface area and body dimensions," Osteoarthritis and Cartilage, vol. 16, no. 1, pp. 34-40, 2008.

[10] D. Kleinloog, J. Stevens, J. Heuberger, P. Spinhoven, and J. van Gerven, "The influence of personality on the sensitivity to subjective effects of $\Delta^{9}$-tetrahydrocannabinol," Psychiatry Research, vol. 220, no. 3, pp. 945-953, 2014.

[11] W. B. Veldhuis, M. van der Stelt, M. W. Wadman et al., "Neuroprotection by the endogenous cannabinoid anandamide and arvanil against in vivo excitotoxicity in the rat: role of vanilloid receptors and lipoxygenases," The Journal of Neuroscience, vol. 23, no. 10, pp. 4127-4133, 2003.

[12] W. Wang, R. Eddy, and J. Condeelis, "The cofilin pathway in breast cancer invasion and metastasis," Nature Reviews Cancer, vol. 7, no. 6, pp. 429-440, 2007.

[13] W.-J. Ma, X. Guo, J.-T. Liu et al., "Proteomic changes in articular cartilage of human endemic osteoarthritis in China," Proteomics, vol. 11, no. 14, pp. 2881-2890, 2011.

[14] N. Chiang, J. M. Schwab, G. Fredman, K. Kasuga, S. Gelman, and C. N. Serhan, "Anesthetics impact the resolution of inflammation," PLoS ONE, vol. 3, no. 4, Article ID e1879, 2008.

[15] J. Rüegg, F. Holsboer, C. Turck, and T. Rein, "Cofilin 1 is revealed as an inhibitor of glucocorticoid receptor by analysis of hormone-resistant cells," Molecular and Cellular Biology, vol. 24, no. 21, pp. 9371-9382, 2004.

[16] F. Fazal, K. M. Bijli, M. Minhajuddin, T. Rein, J. N. Finkelstein, and A. Rahman, "Essential role of cofilin-1 in regulating thrombin-induced RelA/p65 nuclear translocation and intercellular adhesion molecule 1 (ICAM-1) expression in endothelial cells," Journal of Biological Chemistry, vol. 284, no. 31, pp. 21047-21056, 2009.

[17] M. M. Kim, E. Mendis, N. Rajapakse, and S.-K. Kim, "Glucosamine sulfate promotes osteoblastic differentiation of MG63 cells via anti-inflammatory effect," Bioorganic \& Medicinal Chemistry Letters, vol. 17, no. 7, pp. 1938-1942, 2007.

[18] X. Xu, J. A. Kim, and Z. Zuo, "Isoflurane preconditioning reduces mouse microglial activation and injury induced by lipopolysaccharide and interferon-gamma," Neuroscience, vol. 154, no. 3, pp. 1002-1008, 2008.

[19] T. H. Huang, Y. C. Lu, and C. T. Kao, "Low-level diode laser therapy reduces lipopolysaccharide (LPS)-induced bone cell inflammation," Lasers in Medical Science, vol. 27, no. 3, pp. 621627, 2012.

[20] J. D. Leu, Y. W. Chiu, C. C. Lo et al., "Enhanced cellular radiosensitivity induced by cofilin-1 over-expression is associated with reduced DNA repair capacity," International Journal of Radiation Biology, vol. 89, no. 6, pp. 433-444, 2013.

[21] Y.-J. Lee, T.-J. Sheu, and P. C. Keng, "Enhancement of radiosensitivity in H1299 cancer cells by actin-associated protein cofilin,"
Biochemical and Biophysical Research Communications, vol. 335, no. 2, pp. 286-291, 2005.

[22] S. Hashimoto, R. L. Ochs, S. Komiya, and M. Lotz, "Linkage of chondrocyte apoptosis and cartilage degradation in human osteoarthritis," Arthritis \& Rheumatism-Arthritis Care \& Research, vol. 41, no. 9, pp. 1632-1638, 1998.

[23] C. T. Hepper, J. J. Halvorson, S. T. Duncan, A. J. M. Gregory, W. R. Dunn, and K. P. Spindler, "The efficacy and duration of intra-articular corticosteroid injection for knee osteoarthritis: a systematic review of level I studies," Journal of the American Academy of Orthopaedic Surgeons, vol. 17, no. 10, pp. 638-646, 2009.

[24] L. Gallelli, O. Galasso, D. Falcone et al., "The effects of nonsteroidal anti-inflammatory drugs on clinical outcomes, synovial fluid cytokine concentration and signal transduction pathways in knee osteoarthritis. A randomized open label trial," Osteoarthritis and Cartilage, vol. 21, no. 9, pp. 1400-1408, 2013.

[25] A. Pareek and N. Chandurkar, "Comparison of gastrointestinal safety and tolerability of aceclofenac with diclofenac: a multicenter, randomized, double-blind study in patients with knee osteoarthritis," Current Medical Research \& Opinion, vol. 29, no. 7, pp. 849-859, 2013.

[26] D. Bolognini, B. Costa, S. Maione et al., "The plant cannabinoid $\Delta 9$-tetrahydrocannabivarin can decrease signs of inflammation and inflammatory pain in mice," British Journal of Pharmacology, vol. 160, no. 3, pp. 677-687, 2010.

[27] N. Egashira, N. Manome, K. Mishima, K. Iwasaki, R. Oishi, and M. Fujiwara, "Involvement of opioid system in cognitive deficits induced by $\Delta^{9}$-tetrahydrocannabinol in rats," Psychopharmacology, vol. 219, no. 4, pp. 1111-1118, 2012.

[28] Q. Li, H. C. Guo, L. N. Maslov, X. W. Qiao, J. J. Zhou, and Y. Zhang, "Mitochondrial permeability transition pore plays a role in the cardioprotection of CB2 receptor against ischemiareperfusion injury," Canadian Journal of Physiology and Pharmacology, vol. 92, no. 3, pp. 205-214, 2014.

[29] S. Locatelli-Hoops, F. C. Sheen, L. Zoubak, K. Gawrisch, and A. A. Yeliseev, "Application of HaloTag technology to expression and purification of cannabinoid receptor CB2," Protein Expression and Purification, vol. 89, no. 1, pp. 62-72, 2013.

[30] D. V. Gondim, J. C. B. Araújo, A. L. C. Cavalcante et al., “CB1 and $\mathrm{CB} 2$ contribute to antinociceptive and anti-inflammatory effects of electroacupuncture on experimental arthritis of the rat temporomandibular joint," Canadian Journal of Physiology and Pharmacology, vol. 90, no. 11, pp. 1479-1489, 2012.

[31] J. G. Zarruk, D. Fernández-López, I. García-Yébenes et al., "Cannabinoid type 2 receptor activation downregulates strokeinduced classic and alternative brain macrophage/microglial activation concomitant to neuroprotection," Stroke, vol. 43, no. 1, pp. 211-219, 2012.

[32] C. A. Newton and T. W. Klein, "Cannabinoid 2 (CB2) receptor involvement in the down-regulation but not up-regulation of serum IgE levels in immunized mice," Journal of Neuroimmune Pharmacology, vol. 7, no. 3, pp. 591-598, 2012.

[33] T. Kawano, M. Zhu, N. Troiano et al., "LIM kinase 1 deficient mice have reduced bone mass," Bone, vol. 52, no. 1, pp. 70-82, 2013.

[34] F. He and Z.-H. Song, "Molecular and cellular changes induced by the activation of CB2 cannabinoid receptors in trabecular meshwork cells," Molecular Vision, vol. 13, pp. 1348-1356, 2007. 
[35] F. Weis, A. Beiras-Fernandez, D. Hauer et al., "Effect of anaesthesia and cardiopulmonary bypass on blood endocannabinoid concentrations during cardiac surgery," British Journal of Anaesthesia, vol. 105, no. 2, pp. 139-144, 2010.

[36] S. Rom, V. Zuluaga-Ramirez, H. Dykstra, N. L. Reichenbach, P. Pacher, and Y. Persidsky, "Selective activation of cannabinoid receptor 2 in leukocytes suppresses their engagement of the brain endothelium and protects the blood-brain barrier," The American Journal of Pathology, vol. 183, no. 5, pp. 1548-1558, 2013. 


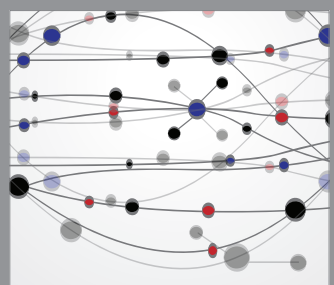

The Scientific World Journal
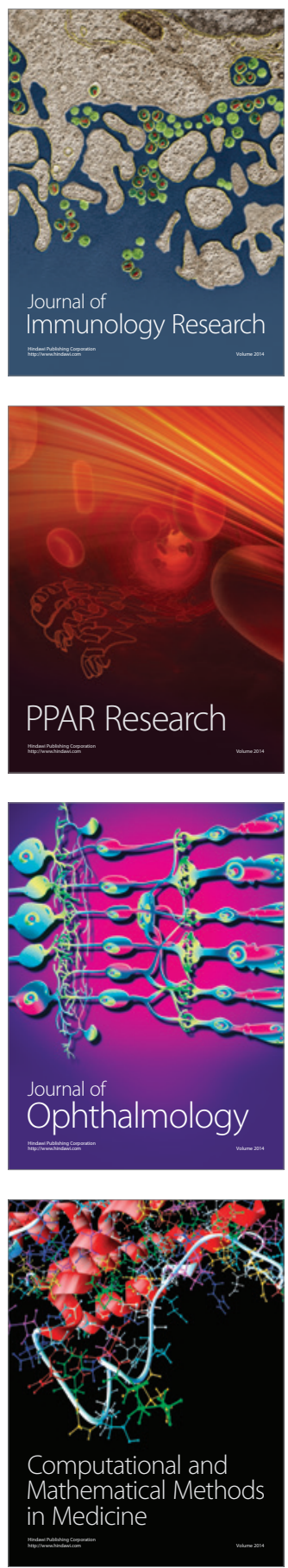

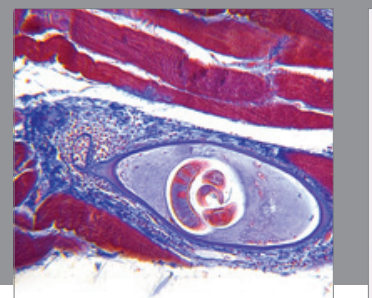

Gastroenterology

Research and Practice
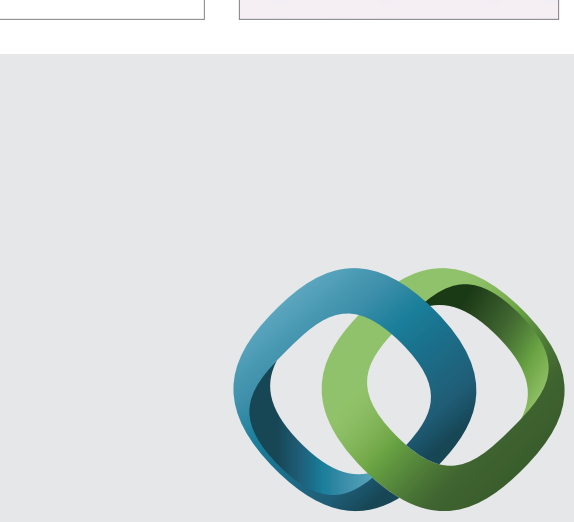

\section{Hindawi}

Submit your manuscripts at

http://www.hindawi.com
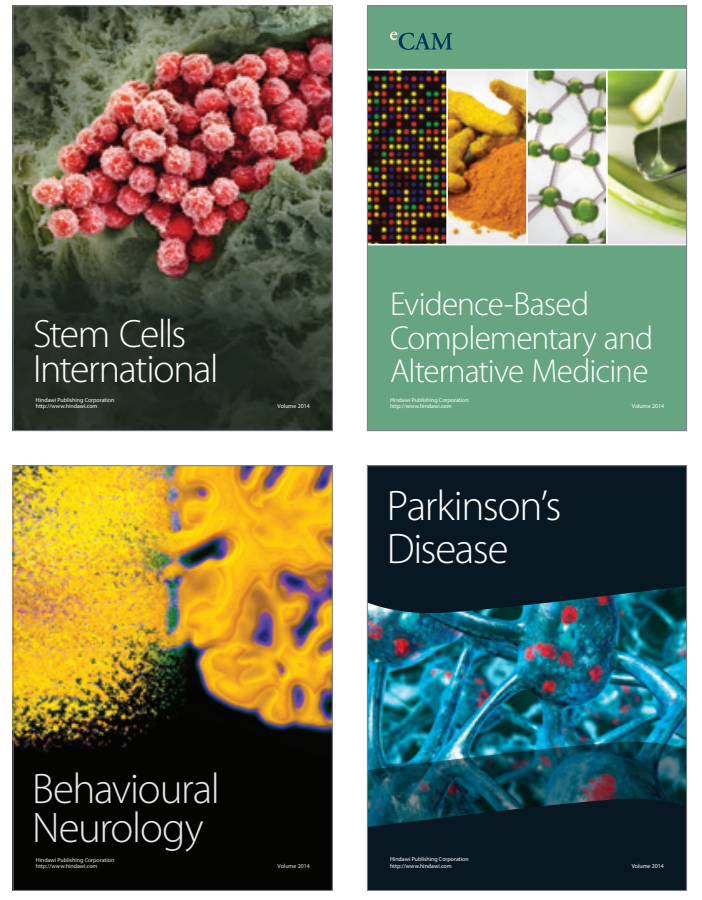
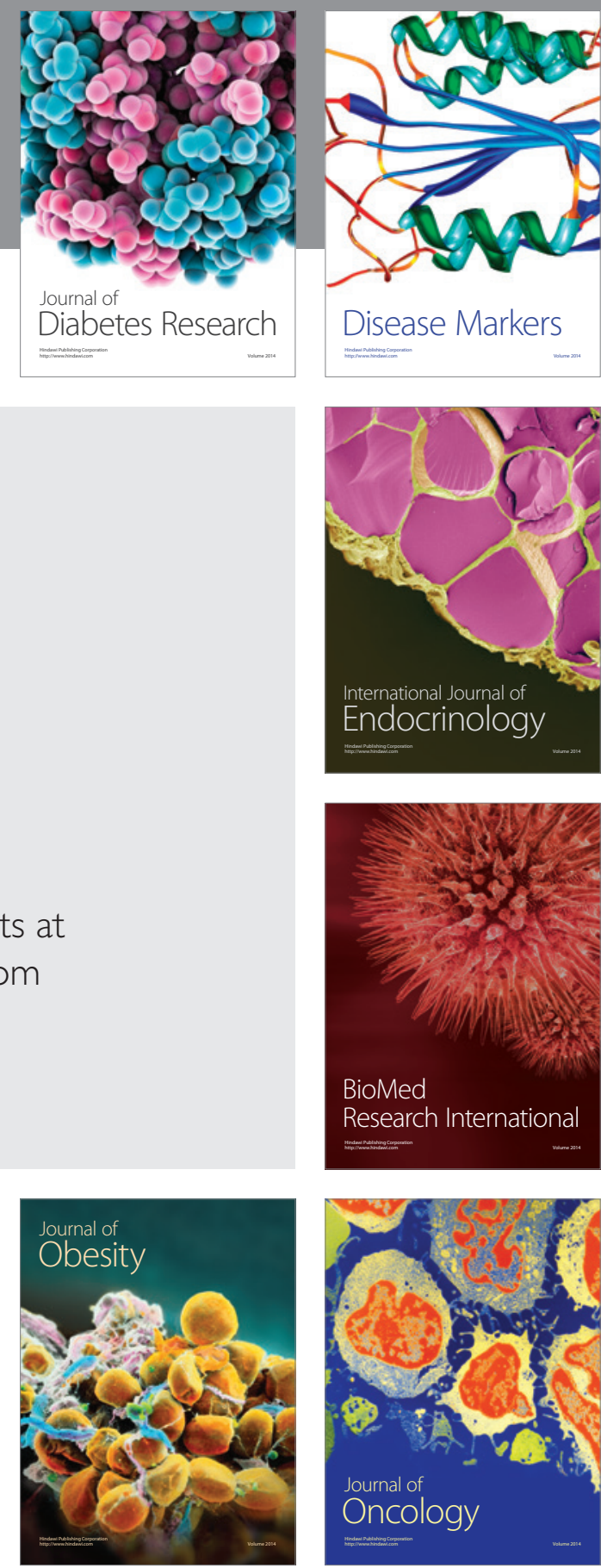

Disease Markers
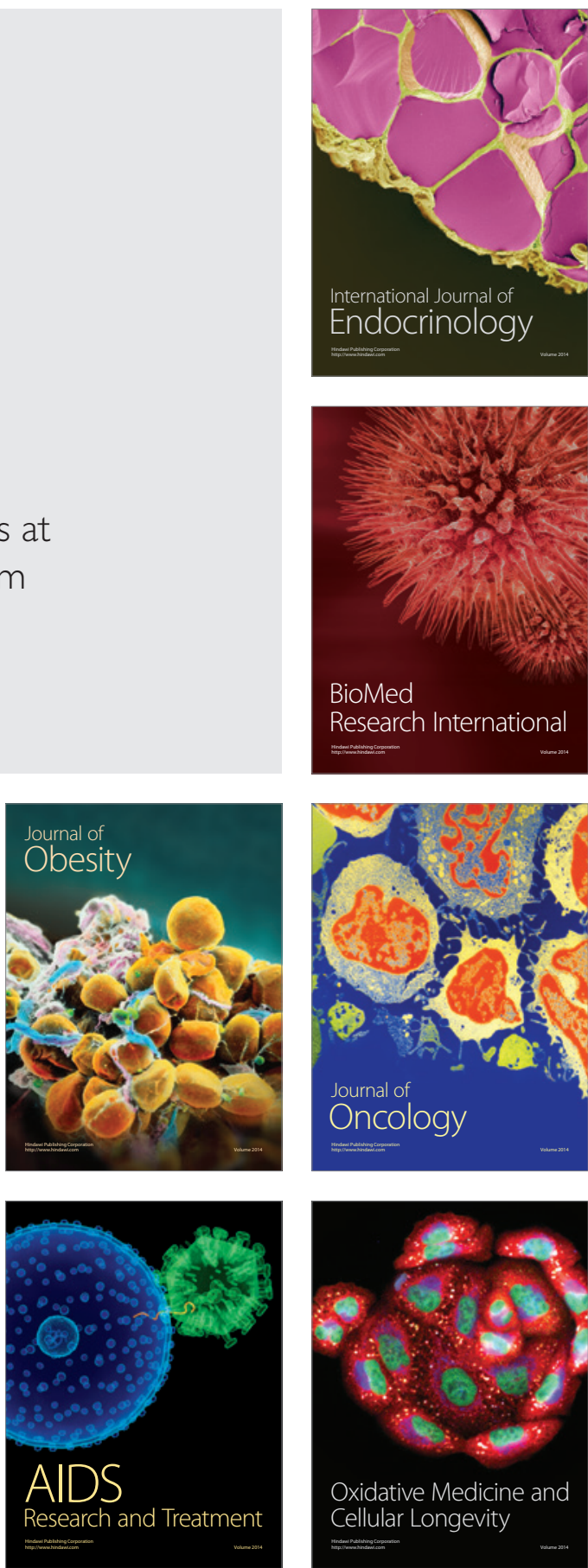